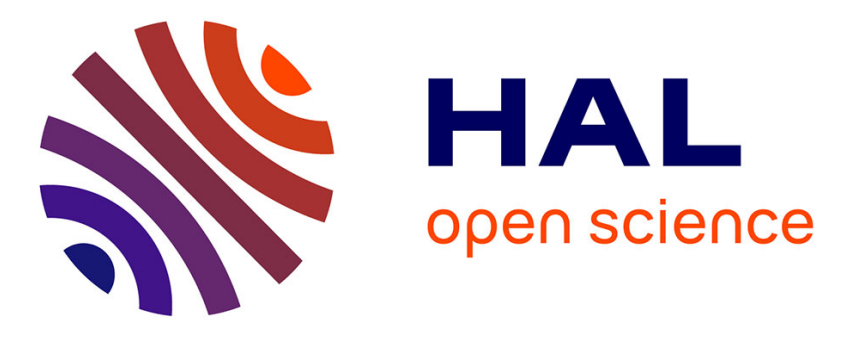

\title{
Oxygen Consumption by Warm Ischemia-Injured Porcine Kidneys in Hypothermic Static and Machine Preservation
}

\author{
Jacques Kaminski, Pierre-Olivier Delpech, Sihem Kaaki-Hosni, Xavier \\ Promeyrat, Thierry Hauet, Patrick Hannaert
}

\section{To cite this version:}

Jacques Kaminski, Pierre-Olivier Delpech, Sihem Kaaki-Hosni, Xavier Promeyrat, Thierry Hauet, et al.. Oxygen Consumption by Warm Ischemia-Injured Porcine Kidneys in Hypothermic Static and Machine Preservation. Journal of Surgical Research, 2019, 242, pp.78-86. 10.1016/j.jss.2019.04.015 . hal-02177529

\section{HAL Id: hal-02177529 \\ https://hal.science/hal-02177529}

Submitted on 22 Oct 2021

HAL is a multi-disciplinary open access archive for the deposit and dissemination of scientific research documents, whether they are published or not. The documents may come from teaching and research institutions in France or abroad, or from public or private research centers.
L'archive ouverte pluridisciplinaire HAL, est destinée au dépôt et à la diffusion de documents scientifiques de niveau recherche, publiés ou non, émanant des établissements d'enseignement et de recherche français ou étrangers, des laboratoires publics ou privés.

\section{(ㅇ)(1) $\$$}

Distributed under a Creative Commons Attribution - NonCommerciall 4.0 International 


\section{Oxygen consumption by Wl-injured porcine kidneys in hypothermic static and machine preservation}

Jacques Kaminski ${ }^{1}$, Pierre-Olivier Delpech ${ }^{1,2}$, Sihem Kaaki-Hosni ${ }^{1}$,

Xavier Promeyrat ${ }^{3}$, Thierry Hauet ${ }^{1,4}$, Patrick Hannaert ${ }^{1}$

Affiliations :

1, INSERM U1082-IRTOMIT, CHU de Poitiers, 2 rue de la Milétrie, 86000 Poitiers, France

2, Service d'Urologie, CHU de Poitiers, 2 rue de la Milétrie, 86000 Poitiers, France

${ }^{3}$, Service d'Urologie et de Chirurgie de la Transplantation, Hôpital Édouard-Herriot, Université Claude-Bernard Lyon 1, 5, place d'Arsonval, 69003 Lyon, France

4, Service de Biochimie, CHU de Poitiers, 2 rue de la Milétrie, 86000 Poitiers, France

Corresponding author: Patrick HANNAERT

INSERM U1082 (IRTOMIT), CHU de la Milétrie 2, rue de la Milétrie - 86021 Poitiers Cedex, France e-mail: patrick.hannaert@univ-poitiers.fr tel: +33-5-49-44-49-54 - fax: +33-5-49-44-49-22 


\section{Authors contributions}

$\mathrm{J}$ Kaminski performed experiments on isolated kidneys, analyzed data, and contributed to the writing of the paper. S Kaaki-Hosni contributed to oxygen determination experiments. PO Delpech and X Promeyrat performed all surgical procedures. T Hauet initiated the project and contributed to the writing of the paper. P Hannaert analyzed the data, performed bibliographical analysis and wrote the paper. 


\section{Abstract}

Static cold storage (SCS) and hypothermic machine perfusion (HMP) are currently standard methods for renal grafts clinical preservation. Both methods are predominantly implemented without the active delivery of oxygen, even for DCD-like kidneys. However, even under severe hypothermia $\left(4-6^{\circ} \mathrm{C}\right)$, kidneys can consume oxygen and produce ATP. What is not established, though, is to what extent and how SCS and HMP compare in terms of oxygen. Using a porcine preclinical model of renal warm ischemia (WI) to compare SCS and HMP methods, we continuously monitored and quantified oxygen level and consumption along preservation; we also determined pre and post-preservation cortical ATP level; values given as median and [min;max] range. One hour WI reduced ATP by $\sim 90 \%$ (from $3.3[1.7 ; 4.5] \mathrm{mmol} / \mathrm{L}$ tissue in Controls). Oxygen consumption $\left(\mathrm{QO}_{2}\right.$, $\mu \mathrm{mol} / \mathrm{min}$ per $100 \mathrm{~g}$ ) was determined from initial solution $\mathrm{PO}_{2}$ decrease (SCS and HMP), and from arterio-venous difference (HMP). In SCS and HMP, $\mathrm{PO}_{2}$ decreased rapidly ( $\mathrm{t}_{1 / 2}$ 1h), from atmospheric levels to $52.9[38.0 ; 65.9]$ and $8.2[3.0,16.0] \mathrm{mmHg}$, respectively. In HMP, $\mathrm{QO}_{2}$ was $2.7[0.4 ; 3.9]$ versus $0.5[0.0 ; 1.3]$ in SCS $(\mathrm{p}<0.05)$; post-preservation ATP amounted to $5.8[3.2 ; 6.5]$ in HMP versus $0.1[0.0 ; 0.2]$ in SCS. Despite hypothermic conditions in SCS or HMP, DCD-like renal grafts require oxygen. Increased oxygen consumption, restored ATP level, and improved histological profile in HMP might explain the established HMP superiority over SCS. These results establish a rational basis for the use of oxygen in hypothermic preservation. Optimal levels required for preservation and graft type variants remain to be determined. 


\section{Running title}

Oxygen use by suboptimal renal grafts in cold preservation

\section{Key words}

Ischemia-reperfusion, Kidney, Preservation, Hypothermic machine perfusion

Static cold storage, Oxygen, ATP 


\section{Abbreviations:}

ATP, Adenosine Tri-Phosphate

DCD, Donation after Circulatory Death

HES, Hematoxylin-Eosin-Safran

HMP, Hypothermic Machine Perfusion

KPS, Kidney Perfusion Solution

NMP, Normothermic Machine Perfusion

PAS, Periodic Acid Schiff

$\mathbf{P O}_{2}$, oxygen partial pressure

SCS, Static Cold Storage

SEM, Standard Error of the Mean

UW, University of Winsconsin

WI, warm ischemia 


\section{Introduction}

Despite the progressive emergence of normothermic preservation and reconditioning methods, such as ex vivo NMP (normothermic machine perfusion) and in situ ECMO (extra-corporeal membrane oxygenation), hypothermic preservation remains the dominant strategy in renal transplantation. Hypothermic preservation is implemented either as static cold storage (SCS) or as hypothermic machine perfusion (HMP), the later being particularly efficient for higher-risk donors ${ }^{1-3}$. Biochemical processes, including ATP-producing oxidative phosphorylation and glycolysis, are slowed by low temperature: for instance, at $7^{\circ} \mathrm{C}$, cellular reactions occur at a residual $\sim 12 \%$ of normothermic rates ${ }^{4}$. However, under hypothermic conditions, even at temperatures as low as $4-6^{\circ} \mathrm{C}$, residual oxygen-dependent (and oxygen-independent) metabolic activities can be significant, oxygen has indeed been shown to be consumed, and ATP can be produced, at least under perfusion ${ }^{5,6}$. Accordingly, the addition of active oxygenation (100\%) to HMP preservation improves post-transplantation outcomes, in preclinical models and in clinical situations, as reviewed ${ }^{7}$. Using a porcine model of WI-injured renal grafts, our laboratory showed that, as compared to passive oxygenation, active oxygenation (100\%) during HMP preservation significantly improved early functional and inflammatory scores, as well as chronic functional and fibrosis scores ${ }^{8}$. However, as in most other studies, oxygen levels were not measured, and one must surmise that, in the "passive" arm for instance, oxygen level of the preservation solution started at atmospheric levels $(21 \%)$. 
In SCS preservation, on the other hand, to our knowledge, no dedicated study evaluated the addition of active oxygen, nor specifically determined oxygen consumption $2,7,9$. Of note though, one study from our laboratory showed that the addition of an oxygen carrier (marine extracellular hemoglobin, M101) during SCS preservation significantly improved functional and histological post-transplantation outcomes, with a notable reduction of fibrosis, in a Pig model of autotransplantation of "normal", uninjured kidneys (WI time $<30 \mathrm{~min}$, SCS $24 \mathrm{~h}$, one month follow-up) ${ }^{10}$. This strongly suggests that the provision of additional oxygen can be beneficial to renal grafts, even under SCS conditions.

In current clinical settings, all SCS and most HMP methods share the common feature of being non-actively oxygenated, i.e. relying on whatever oxygen is present, usually atmospheric oxygen $(\sim 158 \mathrm{mmHg})$; this is the case of the LifePort Kidney Transporter (ORS $\AA$ ). Exceptions which provide for active oxygenation allow for supplementation with either 100\% oxygen $(760 \mathrm{mmHg}$, Kidney Assist-Transport from Organ Assist $\circledast$ and IGL $\circledast$ Waves) or atmospheric oxygen ( IGL Waves).

Few mechanisms can be invoked to explain the benefits of active oxygenation (or oxygen carriers) in SCS or HMP. Obviously, the intrinsic ability of oxygen to sustain mitochondrial ATP production, represents a key player by maintaining cellular structures and repair processes. An increased ATP level during organ preservation is expected to lead to better outcomes and reduced risks of organ dysfunction after transplantation, in animals and human studies ${ }^{9,11}$. However, both in SCS and HMP preservation protocols, and even in preclinical studies, actual levels of renal ATP remain largely undetermined -much like oxygen. The determination of renal graft oxygen levels and consumption, together with tissue ATP levels, should translate into a better understanding of the graft status and its requirements for optimal preservation. Under this rationale, comparing SCS 
and HMP, the two current, non-actively oxygenated, preservation standards, we detrmined i) oxygen levels simultaneously in the preservation solution and within the kidney, and ii) ATP levels before and after WI, and after SCS and HMP preservation. Because the current trend in transplantation is to further extend the donor acceptance criteria, leading to lower quality graft, we performed this experimental study with kidneys pre-injured by one-hour warm ischemia, mimicking DCD grafts (donation after circulatory death) ${ }^{8}$. 


\section{Methods}

Animals and ethics.

Large White male pigs (3 months) were bred at the IBiSA MOPICT platform (INRA, Surgères, Fr), where organ procurement and euthanasia were carried out. All surgical and experimental protocols were performed in accordance with the guidelines of the French Ministry of Agriculture (FMA) for the use and care of laboratories animals, after approval by the FMA, the INRA, and the Poitou-Charentes ethical commitee for animal experimentation.

Surgery and warm ischemia.

Surgery has been described in detail ${ }^{8,12-15}$. Briefly, after general anesthesia, midline abdominal incision, and pedicle clamping, the right kidney was removed by dissection of the vascular pedicle and ureter and transferred into a sterile bag for 60 min warm ischemia $\mathrm{WI}$, and maintained at $37^{\circ} \mathrm{C}$ in a water bath. For oxygen monitoring during warm ischemia, pedicle-clamped, $n=6$ kidneys were used (see figure 1): they were kept in normothermia via a thermostated bath filled with saline, under continuous temperature monitoring (solution and renal cortex). After WI, the kidney was gravimetrically (1 m height) flushed with $500 \mathrm{~mL}$ ice-cold UW® for SCS or KPS® for HMP; all flushings occurred in $<10$ min and yielded whitened kidneys. Figure 1 summarizes the protocol and the use of kidneys. 
Hypothermic preservation - Oxygen and temperature measurements.

For SCS (20h), the kidney was placed in $1 \mathrm{~L}$ ice-cold UW® (Bridge to Life®, London, UK), and placed itself into a styrofoam box, filled with ice. For HMP (20h) the kidney was connected to a LifePort ${ }^{\circledR}$ machine, filled with ice (Lifeport Kidney Transporter 1.0, ORS $\AA_{\text {, }}$ Brussels, Be), set at $35 \mathrm{mmHg}$ pressure.

Cortical temperature was monitored, via $200 \mu$ m-glass thermocouple microsensor (TP200, Unisens $\AA$ ), inserted 3-5 mm below the capsule (signal was fed to a Unisens $\AA$ MicroSensor multimeter). For oxygen monitoring in the HMP perfusate, fiber optic oxygen microsensors (IMP-Pst1, Presens ${ }^{\circledR}$ ) were adapted into the perfusion circuit, at the arterial inlet and venous outlets. Cortical $\mathrm{O}_{2}$ (SCS and HMP) was monitored with Needle-Type optode Oxygen Microsensor (NTH-PSt1, Presens $®$ ), introduced 3-5 mm final under the capsule. Fiber optic oxygen electrodes were connected to a PreSens ${ }^{\circledR}$ oxymeter OXY-4 Mini (4 $\mathrm{min}^{-1}$ sampling). Oxygen signal were converted into pressure and concentration with an Excel® sheet (PreSens $\left.{ }^{\circledR}\right)$. For $\mathrm{O}_{2}$-sensors, two-points calibration was performed for each experiment $\left(100 \% \mathrm{~N}_{2}\right.$ and $100 \%$ air-saturated saline).

\section{Renal tissue ATP}

The ATP content from renal cortical samples, immediately frozen in liquid nitrogen, was measured with the ATP Bioluminescent Assay kit (Sigma®), with 40-70 mg tissue samples. The final ATP concentration is expressed as $\mathrm{mmol} / \mathrm{L}$ of tissue (assuming a tissue density of $1 \mathrm{~g} / \mathrm{mL}$ ). An additional group of $n=5$ kidneys was used for control ATP (i.e. ATP before warm ischemia; see figure 1). 


\section{Histological analysis.}

For histological observations (control, end-CS, end-HMP, end-WI) and for control, $0.5 \times 0.5 \times 1.0 \mathrm{~cm}^{3}$ tissue samples (cortex and medulla) were cut and immersed into $4 \%$ buffered formalin $\left(\mathrm{VWR}^{\circledR}\right)$ for fixation. Fixed samples were then colored with HES/PAS (Hematoxylin-Eosin-Safran/Periodic Acid Schiff) for expert examination and semiquantitative analysis for i) brush-border loss and endoluminal detachment, with the following scoring scale: $\mathbf{0}=$ no lesion; $\mathbf{1},<10 \%$ area; $2,11-25 \%$ area; $\mathbf{3}, 26-50 \%$ area; $\mathbf{4}$, $51-75 \%$ area; $\mathbf{5},>76 \%$ area), and ii) vacuolization and tissue infiltration (number of features per optical field). For both stainings and for each parameter, five slides were read, with six different fields for each $(n=30)$.

\section{Data and statistics.}

Arterio-venous oxygen consumption in HMP was calculated as the product of the perfusion rate with the oxygen arterio-venous difference (expressed in $\mu$ moles $/ \mathrm{min}$ per $100 \mathrm{~g}$ kidney weight). Oxygen consumption from solution concentration was calculated from oxygen decrease between consecutive time-points, under initial rate conditions (10$30 \mathrm{~min})$. Data are presented as median with range [min, max] of $n=5$ values, unless otherwise stated (e.g.for cortical temperature mean \pm SD).

Statistical analysis of oxygen time-course was performed as repeated measures ANOVA (NCSS $\AA^{\text {v } 0.7 .1 .21) . ~ F o r ~ A T P ~ v a l u e s ~ a n d ~ h i s t o l o g i c a l ~ s c o r i n g, ~ s t a t i s t i c s ~ w e r e ~}$ performed as non-parametric one-way ANOVA, with Tukey post-test (Graphpad Prism® v5.01). A $p$ value $<0.05$ was considered significant. 


\section{Results}

Renal oxygen during warm ischemia

Overall, during warm ischemia ( $\mathrm{WI}, 60 \mathrm{~min}$ ), average cortical temperature was $36.0 \pm 0.6$ ${ }^{\circ} \mathrm{C}$ (mean $\pm \mathrm{SD}, \mathrm{n}=60$ time-points): starting from $32.6[29.1 ; 35.1]^{\circ} \mathrm{C}$ at zero time $(\mathrm{n}=6)$, cortical temperature equilibrated at values between 36 and $37^{\circ} \mathrm{C}$ after $10 \mathrm{~min}$; the final WI time-point $\left(60 \mathrm{~min}\right.$ ) was $36.3[35.8 ; 36.6]{ }^{\circ} \mathrm{C}$ (equilibration reache after 5-7min). Oxygen levels of the solution, remained in the $140-160 \mathrm{mmHg}$ range (atmospheric level) throughout WI.

Cortical oxygen level was monitored during the warm ischemic phase, simultaneously with oxygen tension in the solution. Figure 2 plots the bath and cortical oxygen levels ( $n=5$ kidneys, see Methods). It shows that oxygen level in the solution remained in the $140-160 \mathrm{mmHg}$ range, corresponding to atmospheric levels (open symbols). On the other hand, cortical oxygen level was close to zero $(0.1[0.0 ; 2.5] \mathrm{mmHg}$, $\mathrm{n}=8$ time-points; hatched symbols). This confirms that kidneys were hypoxic, quasianoxic, during the ex vivo normothermic ischemic phase.

\section{Renal oxygenation parameters in SCS and HMP}

After WI, kidneys were preserved for 20 hours under SCS (UW), or HMP (KPS; LifePort $\left.{ }^{\circledR}\right)$. During the SCS period, 20h-average cortical temperature was was $2.9 \pm 2.0$ ${ }^{\circ} \mathrm{C}$ (mean $\pm \mathrm{SD}, \mathrm{n}=1,200$ values): starting and final values were $15.0[9.3 ; 22.2]^{\circ} \mathrm{C}(\mathrm{n}=$ 5) and $2.7[2.4 ; 3.0]^{\circ} \mathrm{C}(\mathrm{n}=5)$, respectively, the stable value beeing reached after 5-6 hours. 
During HMP, average cortical temperature was $8.2 \pm 1.0{ }^{\circ} \mathrm{C}$, dropping from 13.2 $[11.1 ; 14.4]^{\circ} \mathrm{C}$ to $7.8[7.7 ; 7.9]^{\circ} \mathrm{C}(\mathrm{n}=5)$, with an apparent half-time for stabilization of $\sim 5$ $\mathrm{h}$ to $6.9 \pm 0.9^{\circ} \mathrm{C}$.

Renal oxygenation parameters during SCS. Figure 3 (main panel) shows the oxygen level (left axis: partial pressure, $\mathrm{mmHg}$; right axis: concentration, $\mu \mathrm{mol} / \mathrm{L}$ ) in the preservation solution (open circles) and in the renal cortex (hatched circles), as monitored throughout the 20h SCS phase ( $n=5$ kidneys). Oxygen level in the solution, starting from atmospheric-equivalent levels $(150-160 \mathrm{mmHg})$ decreased steadily and significantly (F-ratio $=33.13, \mathrm{p}<0.05)$ to stabilize at $51.7[51.4 ; 52.9] \mathrm{mmHg}$ (last $\mathrm{n}=5$ time-points, between 960 and 1,200 min; half-time of decrease $\sim 90 \mathrm{~min}$ ).

In the cortex, the oxygen pressure started from $0.3-0.4 \mathrm{mmHg}$ (between 1 and 30 min), close to the ischemic cortical $\mathrm{PO}_{2}$ (see figure 2).

Since $\mathrm{PO}_{2}$ markedly decreased in the solution, it was possible to calculate (pointto-point) the instantaneous rate of oxygen concentration decrease, i.e. oxygen consumption, $\mathrm{QO}_{2}$. The initial rate of oxygen consumption was extracted from the linear phase of $\mathrm{PO}_{2}$ decrease (10 - 30 min time range; see figure 3 , main panel), i.e. as the average of the $10-20$ and $20-30$ minutes intervals: initial $\mathrm{QO}_{2}$ was $0.6[0.5 ; 0.7] \mu \mathrm{mol} / \mathrm{min}$ per 100g ( $\mathrm{n}=4$ kidneys, one outlier excluded according to Grubbs' test, GraphPad online). Solution-based $\mathrm{QO}_{2}$ is plotted in the inset of figure 2, in the 0 to 400 min range.

Renal oxygenation parameters during HMP. Figure 4 plots oxygen levels in solution (open circles) and in renal cortex (hatched circles), during 20h LifePort machine preservation ( $\mathrm{n}=5$ kidneys, main panel). Under hypothermic machine perfusion, oxygen level in the perfusion solution remained shortly $(10 \mathrm{~min})$ at the atmospheric level $(\sim 145$ 
$\mathrm{mmHg}$ ), then rapidly and significantly $(F=59.44, p<0.05)$ decreased, to a final value of 6.8 [6.6;8.2] $\mathrm{mmHg}$ (last $\mathrm{n}=5$ time-points, between 960 and 1,200 min; half-time 40 min). As for SCS, the initial rate of $\mathrm{QO}_{2}$ in HMP was extracted from the linear phase of $\mathrm{PO}_{2}$ decrease: solution-based $\mathrm{QO}_{2}$ is plotted in the inset of figure 4 , in the 0 to $400 \mathrm{~min}$ range: initial rate was $3.4[2.2 ; 4.6] \mu \mathrm{mol} / \mathrm{min}$ per $100 \mathrm{~g}$ ( $\mathrm{n}=5$ kidneys).

In the cortex, oxygen levels started at $10.2[0 ; 18.9] \mathrm{mmHg}$ (first time-point, 5min)and dropped $(F=4.79, p<0.05)$ to effectively zero afterwards $(0.0-0.3 \mathrm{mmHg})$ within $60 \mathrm{~min}$.

In addition, machine perfusion allows for the determination of the "arterio-venous oxygen consumption", based arterial and venous oxygen concentrations (as reported by respective $\mathrm{O}_{2}$ micro-sensors, see Methods) and on perfusion rate (as reported by the HMP device). In the LifePort machine, the renal perfusion rate rapidly increased from 0 to $40 \mathrm{~mL} / \mathrm{min}$ (in less than $10 \mathrm{~min}$ ), to slowly stabilize at $\sim 50 \mathrm{~mL} / \mathrm{min}$ after $600 \mathrm{~min}$; the $20 \mathrm{~h}$ average perfusion rate was $45.5 \pm 4.5 \mathrm{~mL} / \mathrm{min}$ (mean \pm SEMSD, $\mathrm{n}=20$ ), corresponding to a renal resistance of $\sim 0.7 \mathrm{mmHg}$. $\mathrm{min} / \mathrm{mL}$. The main panel of figure 5 shows the timedependent evolution of arterio-venous renal $\mathrm{QO}_{2}$ during 20h HMP: from the [3.4;4.1] $\mu \mathrm{mol} / \mathrm{min}$ per $100 \mathrm{~g}$ range, renal $\mathrm{QO}_{2}$ significantly decreased $(\mathrm{F}=38.89, \mathrm{p}<0.05)$ to reach $0.4 \mu \mathrm{mol} / \mathrm{min}$ per $100 \mathrm{~g}$ at $120 \mathrm{~min}$ (see inset, zoomed over 0-120 min), then further decreased, very slowly, down to $0.2 \mu \mathrm{mol} / \mathrm{min}$ per $100 \mathrm{~g}$. Initial value of arterio-venous (HMP) QO2 was 3.4-4.1 $\mu \mathrm{mol} / \mathrm{min}$ per $100 \mathrm{~g}$, NS versus solution-based initial consumption (3.4 [2.2;4.6] $\mathrm{\mu mol} / \mathrm{min}$ per $100 \mathrm{~g}$, see above). Conversely, one-way ANOVA comparison of solution-based SCS $(0.6 \mu \mathrm{mol} / \mathrm{min}$ per $100 \mathrm{~g})$ and HMP $(3.4[2.2 ; 4.6] \mu \mathrm{mol} / \mathrm{min}$ per $100 \mathrm{~g})$ consumption indicated a significant difference $(p<0.01)$. 
ATP level of renal cortical tissue. Figure 6 summarizes ATP results. Renal cortical ATP in the control (non-ischemic) group was $3.3[1.7 ; 4.6] \mathrm{mmol} / \mathrm{L}$ of tissue. After 60 minutes of warm ischemia, the ATP level was $0.3[0.2 ; 0.6] \mathrm{mmol} / \mathrm{L}(\mathrm{p}<0.01 \mathrm{vs}$ control). After 20 hours of SCS, the ATP content of the kidneys was 0.06 [0.04;0.09] mmol/L (NS vs WI), whereas it was $5.8[3.2 ; 6.5] \mathrm{mmol} / \mathrm{L}$ in HMP $(p<0.01$ vs WI).

Histological analysis. Figure 7a shows representative HES and PAS-colorations of cortical and medullary tissue sections of the four experimental groups. Figure $7 \mathrm{~b}$ summarizes the corresponding histological scores. It can be seen that WI60 induced significant histological injuries versus control (brush border loss, endoluminal detachment, vacuolization and infiltration). All four parameters were significantly improved by HMP versus SCS, although not normalized to control (except for tissue infiltration). Finally, brush border loss was potentiated by SCS versus WI60 (by about two-fold), and HMP did not restore control level.

\section{Discussion}

Oxygen supplementation during hypothermic preservation is the focus of preclinical and clinical studies ${ }^{7}$, but, paradoxically oxygenation parameters are often ignored and left unquantified (i.e. oxygen level and/or consumption). In non-actively oxygenated hypothermic methods (where either static solution is enclosed in a sealed recipient, or perfusate solution is recirculated without possible or significant re-equilibration with atmospheric oxygen), oxygen-related parameters are usually not measured, e.g. because graft requirements are assumed to be minimal.

On the other hand, we reported, with our porcine model of renal autotransplantation that i) the addition of an hemoglobin-based oxygen carrier to SCS preservation does improve 
post-transplant outcomes ${ }^{10,15}$, and ii) active oxygenation $\left(100 \% \mathrm{O}_{2}\right)$ in HMP improves post-transplantation function recovery of Wl-injured kidneys ${ }^{8}$. In other words, as reviewed ${ }^{7}$, renal grafts can draw benefit from oxygen under hypothermic preservation. On the other hand, due to the expanding use of suboptimal grafts, HMP preservation has now grown more frequent than the simpler and cheaper SCS preservation, at least in european and north-american countries. But, as for SCS, oxygen-related parameters are most generally 'ignored'. Some rare preclinical studies addressed oxygen issues, though. For instance, one porcine study promoted the determination of oxygen consumption for viability assessment ${ }^{6}$. At least in the cortex, oxygen can be considered as a proxy for ATP, the cell energetic currency. However, because of technical and logistical easons, ATP is even more difficult to monitor. Accordingly, very few studies, mostly preclinical, did measure ATP 16,17 .

Thus, the monitoring of renal graft oxygen levels and consumption, together with tissue ATP levels, will help understand graft status and requirements for better, if not optimal, preservation. To address the current clinical context, we used renal grafts injured by 60 minutes warm ischemia (WI) ${ }^{18,19}$, UW for SCS, and KPS and the LifePort ${ }^{\circledR}$ system for HMP.

\section{Oxygen is consumed and limiting in non-oxygenated SCS and HMP}

In SCS and $\mathrm{HMP}, \mathrm{PO}_{2}$ of the preservation solution decreased rapidly, from atmospheric level, then stabilized. Decreases of perfusion $\mathrm{PO}_{2}$ in $\mathrm{HMP}$ were reported in uninjured (WI $<10 \mathrm{~min}$ ) porcine kidneys ${ }^{6}$ and (45min WI-injured) canine kidneys ${ }^{20}$. However, in the first case data are not presented ('...PO $\mathrm{PO}_{2}$ of the perfusate approached zero within minutes..') ${ }^{6}$, while in the second, only initial and final $\mathrm{PO}_{2}$ value are reported (from $170 \mathrm{mmHg}$ at 
zero time to $25 \mathrm{mmHg}$ after $24 \mathrm{~h} \mathrm{HMP}$, LifePort) ${ }^{20}$. To our knowledge, oxygen level has not been reported in SCS.

SCS exploratory experiments confirmed that solution $\mathrm{PO}_{2}$ was stable for $24 \mathrm{~h}$ (150 $\mathrm{mmHg}$ ), whereas it decreased and stabilized with a WI-injured kidney (not shown). We conclude that, in hypothermia, injured kidneys do consume oxygen, despite the low temperature and the static condition (no perfusion and no transport-related consumption). Of note, the SCS and the HMP systems used in the presenet study were open to atmosphere (electrodes, holding arm), which suggests that in clinics oxygen becomes limiting even faster than observed here (<60-90min). Finally, our conclusion that oxygen is limiting in non-oxygenated SCS and HMP agrees with reports that a short, postischemic/pre-transplantation period of active graft oxygenation $\left(1-2 \mathrm{~h}, \mathrm{PO}_{2}>500 \mathrm{mmHg}\right)$ improves kidney function recovery ${ }^{21,22}$. This was also shown in HMP or retrograde persufflation of the liver ${ }^{23}$.

In SCS, solution-based oxygen consumption was $0.6 \mu \mathrm{mol} / \mathrm{min}$ per $100 \mathrm{~g}$, whereas in $\mathrm{HMP}$, it was $3.4 \mu \mathrm{mol} / \mathrm{min}$ per $100 \mathrm{~g}$, the later being not significantly different from the arterio-venous calculation in $\mathrm{HMP}\left(\mathrm{av}-\mathrm{QO}_{2} 3.7 \mu \mathrm{mol} / \mathrm{min}\right.$ per $\left.100 \mathrm{~g}\right)$. Of note, in HMP, the initial decrease of cortical oxygen (from 10-15 to $0 \mathrm{mmHg}$ ), occurred simultaneously with the initial decrease in the solution.

To our knowledge, $\mathrm{QO}_{2}$ has not been reported in SCS, likely because this was considered irrelevant. Conversely, in $\mathrm{HMP} \mathrm{QO}_{2}$ of Pig kidneys has been reported to amount to $\sim 1,6 \mu \mathrm{mol} / \mathrm{min}$ per $100 \mathrm{~g}(\mathrm{WI}<10 \mathrm{~min})^{6}$, a value close to the present one $(3.7$ $\mu$ mol.min per $100 \mathrm{~g}, \mathrm{WI}=60 \mathrm{~min})$. Starting from a total physiological oxygen consumption (transport-related + basal $\sim 200 \mu$ mol.min per kidney ${ }^{24}$ ), and applying a $20 \%$ basal fraction, one obtains $\sim 40 \mu \mathrm{mol} / \mathrm{min}$ per $100 \mathrm{~g}$ for non-transport related costs. After 
temperature-dependent reduction, hypothermic $\mathrm{QO}_{2}$ would amount to $\sim 5 \mu \mathrm{mol} / \mathrm{min}$ per $100 \mathrm{~g}$, very close to and, supporting our determinations. This further supports the notion that, in hypothermic preservation, normal or injured kidneys do consume oxygen. Finally, it also suggests that warm ischemia may not modify basal consumption, although this remains to be established.

In the preservation solution, the low oxygen steady-state indicates that the transfer capacity, via the solution and the capsule, to the cortical parenchyme is limited (and limiting) with respect to intrarenal consumption. This observation is supported by exploratory experiments from our group, showing that solution $\mathrm{PO}_{2}$ not only decreases with time, but that this decrease is more pronounced if electrodes are positioned "close to" versus "far from" the kidney: for instance, between 10 and $15 \mathrm{~h}$ the 'close' electrodes (2-3 $\mathrm{cm})$ reported 6-34 $\mathrm{mmHg} \mathrm{PO}_{2}$ lower than the distant'electrodes $(5-7 \mathrm{~cm} ; \mathrm{n}=2$ healthy kidneys and $n=2$ WI-injured kidneys). This is also in line with the report of a kidney 'surface $\mathrm{PO}_{2}$ ' of $5-10 \mathrm{mmHg}$ in the SCS solution, versus $100-150 \mathrm{mmHg}$ in HMP 25. Furthermore, we suggest that the significantly higher steady-state values of solution oxygen in SCS $(\sim 52 \mathrm{mmHg})$ versus HMP $(\sim 8 \mathrm{mmHg})$ indicates that HMP kidneys consume more oxygen than SCS kidneys. Indeed, at $35 \mathrm{mmHg}$ perfusion pressure, filtration still occurs, proportional to renal flow (since perfusion pressure is below the autoregulatory range), roughly amounting to $\sim 30 \%$ of normal filtration. This is comforted by published reports of urine production during HMP preservation $\left(\sim 0.1 \mathrm{~mL} / \mathrm{min}\right.$ per $\left.100 \mathrm{~g}{ }^{26}\right)$ and our unpublished observations. A crude estimation indicates that under our HMP conditions, oxygen consumption should range 6-7 $\mu \mathrm{mol} / \mathrm{min}$ per $100 \mathrm{~g}$, relatively close to our 3-4 $\mu \mathrm{mol} / \mathrm{min}$ per $100 \mathrm{~g}$ measurement (see above). 


\section{ATP level and histological evaluation in HMP and SCS}

Beneficial effects of oxygen supplementation in hypothermic preservation are acknowledged, i) in HMP and for high-risk kidneys, and ii) as involving some restoration of ATP ${ }^{27}$. More surprisingly, even under SCS conditions, direct $\left(100 \% \mathrm{O}_{2}{ }^{28}\right)$ or indirect (M101 carrier $\left.{ }^{10}\right)$ oxygen supplementation is able to provide improvements as well.

As opposed to the renal medulla, cortical ATP synthesis heavily relies on oxygen and mitochondrial phosphorylation. Normal porcine cortical tissue $\mathrm{PO}_{2}$ is $\sim 45 \mathrm{mmHg}^{29}$. Here, shortly after the start of the WI period (<5 min), cortical oxygen barely exceeded electrode sensitivity $(0.4-0.8 \mathrm{mmHg})$, even though the solution was in contact with atmosphere. Accordingly, end-ischemic ATP was strongly reduced (nb: control ATP, was similar to other reports ${ }^{25}$ ). ATP levels (after SCS) of "marginal" kidneys (WI 40min) have been reported to amount to $\sim 0.16 \mu \mathrm{mol} / \mathrm{g}$ tissue (or $\sim 0.2 \mathrm{mM}$ ), in the Pig ${ }^{23}$; this represents a $80-90 \%$ reduction versus control ATP, as we observed here.

After SCS of WI-injured kidneys, ATP remained very low, indicating that these grafts were unable to resynthetize ATP, whereas ATP reached back control level after HMP. These results suggest that ATP was beeing produced during HMP preservation, in excess to consumption. Few studies addressed the ATP production-consumption balance in hypothermic conditions. A careful bibliographical analysis evidenced a patent lack of information about ATP levels in renal graft preservation. Most generally, neither absolute ATP levels nor healthy control value are given (see Bagul and coworkers for a porcine model ${ }^{30}$, and Ravaioli et al., for human discarded kidneys ${ }^{11}$ ). Nevertheless, supporting our present observations, two porcine studies, performed on did show marked benefits of HMP versus SCS in terms of graft ATP levels. First, ATP resynthesis was observed in oxygenated HMP but not in SCS, in a WI-injured graft model ${ }^{31}$. Second, 
a 2.5-fold ATP post-HMP increase was reported versus post-SCS in a WI-injured kidneys ( $\leq 30 \mathrm{~min}$ ) model ${ }^{32}$. In HMP, the "steady-state" solution oxygen was lower than in SCS, whereas, end-preservation ATP was higher in HMP.

Finally, considering tissue integrity outcomes, by showing less injured tissues, histological analysis confirmed HMP superiority over SCS, in agreement with the increased oxygen consumption and higher levels of ATP. It is important to note though that the ATP 'restoration' may not be the sole factor involved in renal tissue "repair" during hypothermic preservation since SCS itself was able to partially improve the histological profile.

\section{Conclusion}

Grafts under SCS or HMP preservation are rarely biopsied, while three-months and oneyear post-transplantation biopsies are common in clinical practice, allowing for histological analysis and grading. Ex vivo quality assessment of renal grafts is limited to visual inspection, before and after flushing (color, patchiness), and to renal resistance in HMP. Oxygen monitoring requires a dedicated setup, and no current perfusion system is equipped with oxygen sensors ${ }^{7}$. Even when actively oxygenated, no available system allows for oxygen measurements. Thus, oxygen and ATP are seldom measured, much less comparatively in SCS and HMP. Oxygen measurement (and consumption calculation) one the one hand, and high-resolution NMR spectroscopy or electrode-based determinations of tissue ATP, as alternatives, on the other hand, would constitute significant improvements, widening the currently restricted panel of clinical evaluation criteria with physiologically relevant and quantitative indexes ${ }^{33}$. 


\section{Acknowledgments}

This work was performed in the U1082 INSERM (Institut National de la Santé et de la Recherche Médicale) research unit (dir. $\operatorname{Pr}$ T. Hauet), by the Centre HospitaloUniversitaire $(\mathrm{CHU})$ de Poitiers, and by the Université de Poitiers. It was supported by the CNRS (Centre National de la Recherche Scientifique) for PH salarial cost. JK was supported by a grant from the ANR (2011, RPIB-013, HemoPerf).

We are indebted to Nicolas Chatauret for the initial setting up of the SCS and HMP oxygen measurements, and for helpful discussion. We acknowledge Abdesalam Kasil's help with animal surgery and kidney withdrawaland expert histological slides preparation by Virginie Ameteau. We are grateful to Dr Jérôme Roumy for interest and discussion. Finally, we are greatly indebted to the surgical platform MOPICT (INRA, Surgères) and members for excellent and expert technical support: William Hébrard and Irène Launay (INRA, Surgères), and Pierre Couturier (CHU, Service de Biochimie). 


\section{Conflict of interest statement}

No conflict of interest, financial or otherwise are declared by all authors. 


\section{References:}

1. Jochmans, I., Nicholson, M. L. \& Hosgood, S. A. Kidney perfusion: Some like it hot others prefer to keep it cool. Curr. Opin. Organ Transplant. 22, 260-266 (2017).

2. Golbo, N. \& Monbaliu, D. Temperature and oxygenation during organ preservation: Friends or foes? Curr. Opin. Organ Transplant. 22, 290-299 (2017).

3. Jochmans, I. et al. Past, Present, and Future of Dynamic Kidney and Liver Preservation and Resuscitation. Am. J. Transplant. 16, 2545-2555 (2016).

4. Folkert O. Belzer, J. H. S. Principles of solid-organ preservation by cold storage. Transplantation 45, 673-676 (1988).

5. Stubenitsky, B. M., Ametani, M., Danielewicz, R., Southard, J. H. \& Belzer, F. O. Regeneration of ATP in kidney slices after warm ischemia and hypothermic preservation. Transpl. Int. 8, 293-297 (1995).

6. Weegman, B. P. et al. Continuous real-time viability assessment of kidneys based on oxygen consumption. in Transplantation Proceedings 42, 2020-2023 (2010).

7. O'Callaghan, J. M. et al. Supplemental oxygen during hypothermic kidney preservation: A systematic review. Transplant. Rev. 31, 172-179 (2017).

8. Thuillier, R. et al. Benefits of active oxygenation during hypothermic machine perfusion of kidneys in a preclinical model of deceased after cardiac death donors. $J$. Surg. Res. 184, 1174-1181 (2013). 
9. Hosgood, S. A., Nicholson, H. F. L. \& Nicholson, M. L. Oxygenated kidney preservation techniques. Transplantation 93, 455-459 (2012).

10. Thuillier, R. et al. Supplementation with a new therapeutic oxygen carrier reduces chronic fibrosis and organ dysfunction in kidney static preservation. Am. J. Transplant. 11, 1845-1860 (2011).

11. Ravaioli, M. et al. Strategies to restore adenosine triphosphate (ATP) level after more than 20 hours of cold ischemia time in human marginal kidney grafts. Ann. Transplant. 23, 34-44 (2018).

12. Favreau, F. et al. Anti-thrombin therapy during warm ischemia and cold preservation prevents chronic kidney graft fibrosis in a DCD model. Am. J. Transplant. 10, 30-39 (2010).

13. Allain, G. et al. Development of a preclinical model of donation after circulatory determination of death for translational application. Transplant. Res. 3, 13 (2014).

14. Tillet, S. et al. Kidney graft outcome using an anti-Xa therapeutic strategy in an experimental model of severe ischaemia-reperfusion injury. Br. J. Surg. 102, 132142; discussion 142 (2015).

15. Mallet, V. et al. Dose-ranging study of the performance of the natural oxygen transporter HEMO2life in organ preservation. Artif. Organs 38, 691-701 (2014).

16. Buchs, J. B. et al. DCD Pigs' Kidneys Analyzed by MRI to Assess Ex Vivo Their Viability. Transplantation 97, 148-153 (2014).

17. Minor, T., Efferz, P. \& Lüer, B. Hypothermic reconditioning by gaseous oxygen persufflation after cold storage of porcine kidneys. Cryobiology 65, 41-44 (2012). 
18. Hosgood, S. A., Shah, K., Patel, M. \& Nicholson, M. L. The effect of prolonged of warm ischaemic injury on renal function in an experimental ex vivo normothermic perfusion system. J. Transl. Med. 13, (2015).

19. Delpech, P. O. et al. Inhibition of complement improves graft outcome in a pig model of kidney autotransplantation. J. Transl. Med. 14, (2016).

20. Lindell, S. L., Muir, H., Brassil, J. \& Mangino, M. J. Hypothermic Machine Perfusion Preservation of the DCD Kidney: Machine Effects. J. Transplant. 2013, 1-7 (2013).

21. Hoyer, D. P. et al. Influence of oxygen concentration during hypothermic machine perfusion on porcine kidneys from donation after circulatory death. Transplantation 98, 944-950 (2014).

22. Kron, P. et al. Short, cool, and well oxygenated - HOPE for kidney transplantation in a rodent model. Ann. Surg. 264, 815-822 (2016).

23. Minor, T., Von Horn, C. \& Paul, A. Role of temperature in reconditioning and evaluation of cold preserved kidney and liver grafts. Curr. Opin. Organ Transplant. 22, 267-273 (2017).

24. Juillard, L. et al. Validation of renal oxidative metabolism measurement by positronemission tomography. in Hypertension 50, 242-247 (2007).

25. Minor, T., Sitzia, M. \& Dombrowski, F. Kidney transplantation from non-heart-beating donors after oxygenated low-flow machine perfusion preservation with histidine tryptophan - ketoglutarate solution. Transplant. Int. 17, 707-712 (2005). 
26. Blum, M. F. et al. Comparison of normothermic and hypothermic perfusion in porcine kidneys donated after cardiac death. 35-45 (2018). doi:10.1016/j.jss.2017.04.008.Comparison

27. Taylor, M. J. \& Baicu, C. Current State of Hypothermic Machine Perfusion Preservation of Organs : The Clinical Perspective. Cryobiology 60, S20-S35 (2010).

28. Maathuis, M. H. J. et al. Improved kidney graft function after preservation using a novel hypothermic machine perfusion device. Ann. Surg. 246, 982-989 (2007).

29. Warner, L. et al. Regional decreases in renal oxygenation during graded acute renal arterial stenosis: a case for renal ischemia. Am J Physiol Regul Integr Comp Physiol 296, R67-71 (2009).

30. Bagul, A. et al. Experimental renal preservation by normothermic resuscitation perfusion with autologous blood. Br. J. Surg. 95, 111-118 (2008).

31. Lazeyras, F. et al. Detection of ATP by 'in line'31P magnetic resonance spectroscopy during oxygenated hypothermic pulsatile perfusion of pigs' kidneys. Magn. Reson. Mater. Phys. Biol. Med. 25, 391-399 (2012).

32. La Manna, G. et al. An in vivo autotransplant model of renal preservation: Cold storage versus machine perfusion in the prevention of ischemia/reperfusion injury. Artif. Organs 33, 565-570 (2009).

33. Kerforne, T. \& Saint-yves, T. Inhibition of coagulation proteases Xa and Ila decreases ischemia - reperfusion injuries in a preclinical renal transplantation model. 95-107 (2016). doi:10.1016/j.trsl.2016.07.014 
34. Willford, D. C., Hill, E. P. \& Moores, W. Y. THEORETICAL ANALYSIS OF OXYGEN TRANSPORT DURING HYPOTHERMIA David C. Willford, PhD, ${ }^{*}$ Esther P. Hill, PhD, ${ }^{*}$ and William Y. Moores, MD'p. J Clin Monit 2, 30-43 (1986). 


\section{Figure and legends to figures}

Figure 1: Protocol flow chart

Figure 2: Time-course of oxygen in the solution and cortex during warm ischemia

Figure 3: Renal oxygenation during 20 hours SCS - Oxygen consumption.

Figure 4: Renal oxygenation during 20 hours HMP preservation - Oxygen consumption

Figure 5: Arterio-venous consumption of oxygen during 20 hours HMP

Figure 6 : ATP in the renal cortex, in Control, End-WI, End-SCS and End-HMP

Figure 7a : HES and PAS colorations of Control, End-WI, End-SCS and End-HMP

Figure $7 \mathrm{~b}$ : Semi-quantitative histological scoring of renal tissue sections 
Legend to figure 1: Protocol flow chart 
Legend to figure 2: Figure depicts the time-course of oxygen levels in the solution and in the cortex during the 60 minutes warm ischemia (median and [range], $n=5$ ). Monitoring of renal temperature and oxygen level was performed with electrodes inserted into the cortex (3-5 mm depth). Open circles represent oxygen pressure in the solution; hatched symbols correspond to levels of oxygen pressure in the renal cortex. 
Legend to figure 3: Figure shows the time-course of oxygen levels in the solution and in the cortex during 20 hours of SCS preservation (median and [range], $n=5$ ): open symbols, solution; hatched symbols, cortex (inset). The left y-axis represents oxygen partial pressure, in $\mathrm{mmHg}$, whereas the right one represents the corresponding oxygen concentration, in $\mu \mathrm{M}$ (calculated using a temperature-adjusted oxygen solubility, see Methods). The decrease in the solution features at least two components but this was not further analyzed. The apparent half-time of the decrease is $\sim 90 \mathrm{~min}$; the final, steadystate value is 51.7 [51.4;52.9] $\mathrm{mmHg}$ ( $\mathrm{n}=5$ time-points, between 960 and 1,200 $\mathrm{min}$ ). Average temperature (20h) was $2.9 \pm 2.0^{\circ} \mathrm{C}$ (mean $\pm \mathrm{SD}, \mathrm{n}=1,200$ values, see Results for details); it was $15-8{ }^{\circ} \mathrm{C}$ during the first $60 \mathrm{~min}$ (corresponding to a temperaturedependent 5-8 fold reduction of reaction rates, assuming $Q_{10}=2$, see ${ }^{34}$ ). The inset shows the oxygen consumption (based on initial decrease of oxygen in the solution), plotted between 0-420 $\mathrm{min}(0-7 \mathrm{~h})$; initial rate was in the $0.5-0.7 \mu \mathrm{mol} / \mathrm{min}$ per $100 \mathrm{~g}$. 
Legend to figure 4: Figure plots oxygen levels in solution (open circles, $n=5$ ) and in renal cortex (hatched circles, $n=5$ ), during 20 hours HMP (LifePort ${ }^{\circledR}$ ). The left $y$-axis represents $\mathrm{PO}_{2}(\mathrm{mmHg})$, while the right one represents corresponding concentration $(\mu \mathrm{M}$, see Methods). The apparent half-time of the decrease is $\sim 40 \mathrm{~min}$, and the steady-state value is $6.8[6.6 ; 8.2] \mathrm{mmHg}$. Time-averaged temperature $(20 \mathrm{~h})$ was $8.2 \pm 1.0^{\circ} \mathrm{C}$ (mean \pm $\mathrm{SD}$ ); it was $\sim 12{ }^{\circ} \mathrm{C}$ during the first $60 \mathrm{~min}$ ( $\sim 6$-fold reduction of reaction rates). The inset plots the oxygen consumption (calculated from initial decrease of oxygen in the solution) between $0-400 \mathrm{~min}$, which is in the range $2.2-4.6 \mu \mathrm{mol} / \mathrm{min}$ per $100 \mathrm{~g}$. 
Legend to figure 5: Figure plots the arterio-venous consumption in HMP preservation, calculated as the product of renal perfusion rate by the arterio-venous oxygen difference (see Methods). Please note that the vertical axis is not oxygen (as is in figure 2, 3 and 4) but oxygen consumption. Initial renal graft consumption in HMP was [3.4;4.1] $\mu \mathrm{mol} / \mathrm{min}$ per $100 \mathrm{~g}$. The inset represents the same results, zoomed over the first 120 minutes 
Legend to figure 6: ATP concentration in renal cortical tissue (median and [range], $\mathrm{n}=5$ per group). Control was measured before warm ischemia, while end-ischemic ATP was measured at the end of the 60 minutes period of warm ischemia (End-WI). End-SCS and End-HMP, correspond to renal cortical ATP of kidneys submitted to $60 \mathrm{~min}$ WI followed by 20 hours SCS and 20 hours HMP preservation, respectively. ATP is given as mmol/L of tissue (conservatively equivalent to $\mu$ moles ATP perg wet tissue). 


\section{Legends to figure $7 a$ and $7 b$}

Figure 7a: Representative HES and PAS colorations of renal tissue, split into cortical (upper lines of each quadrant) and medullary (lower lines) areas. Each quadrant is further split vertically, into left and right columns, respectively showing HES and PAS staining.

Arrows exemplify: brush border loss (red), endoluminal detachment (blue), vacuolization (black), and interstitially infiltrated cells (yellow). The black bar represents $100 \mu \mathrm{m}$.

Figure 7b: Semi-quantitative histological scoring (see Methods). Panel A, Brush border loss scores (upper left); panel B, Endoluminal detachment scores (upper right); panel C, Vacuolization scores (lower left); panel D, Infiltration (lower right). Statistics performed as ANOVA one-way, with Tukey's post-test for multiple comparisons: ${ }^{*}, p<0.05 ;{ }^{* *}, p<$ $0.01 ;{ }^{* * *}, p<0.001 ; n s$, not significant. 


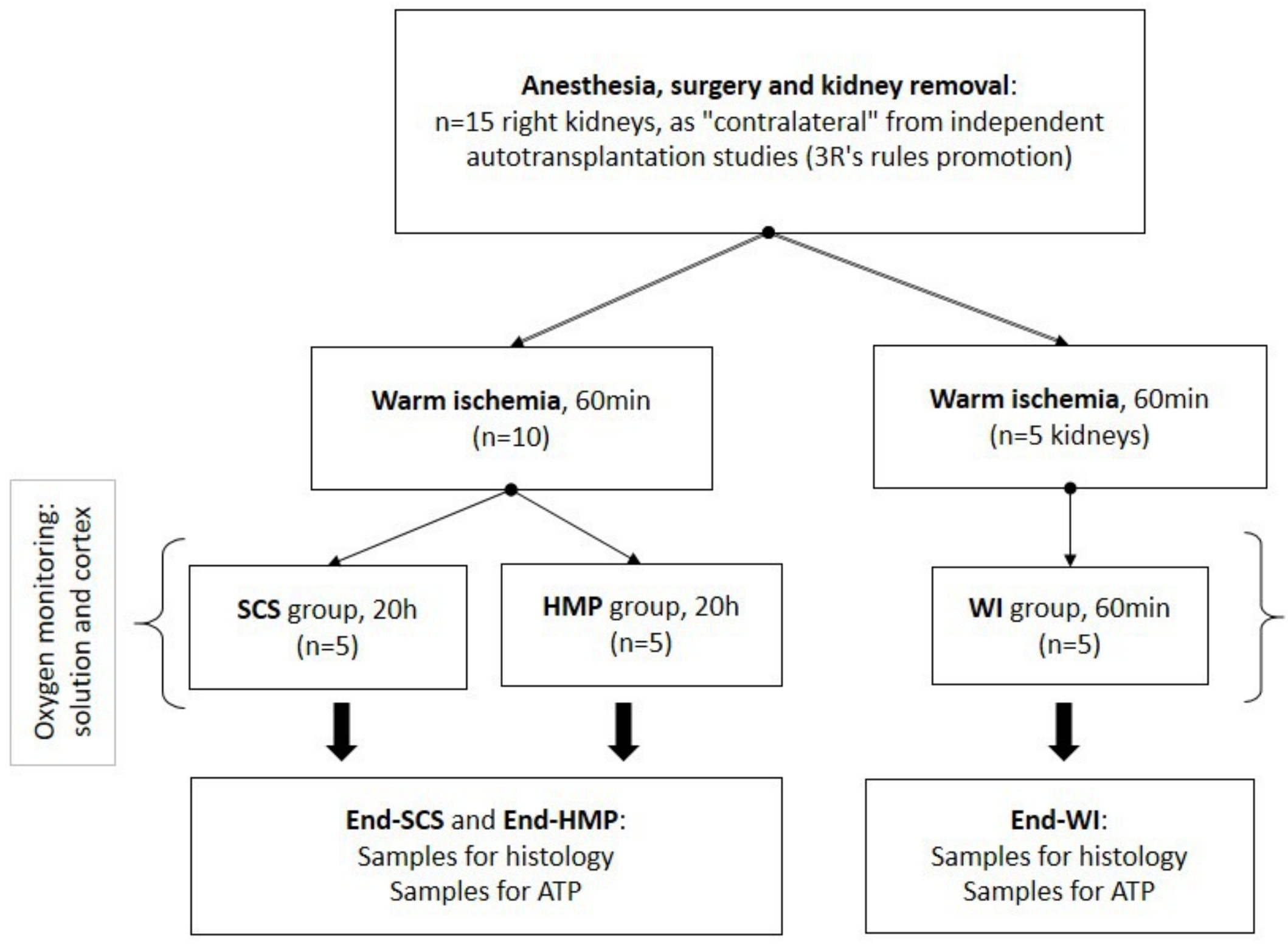




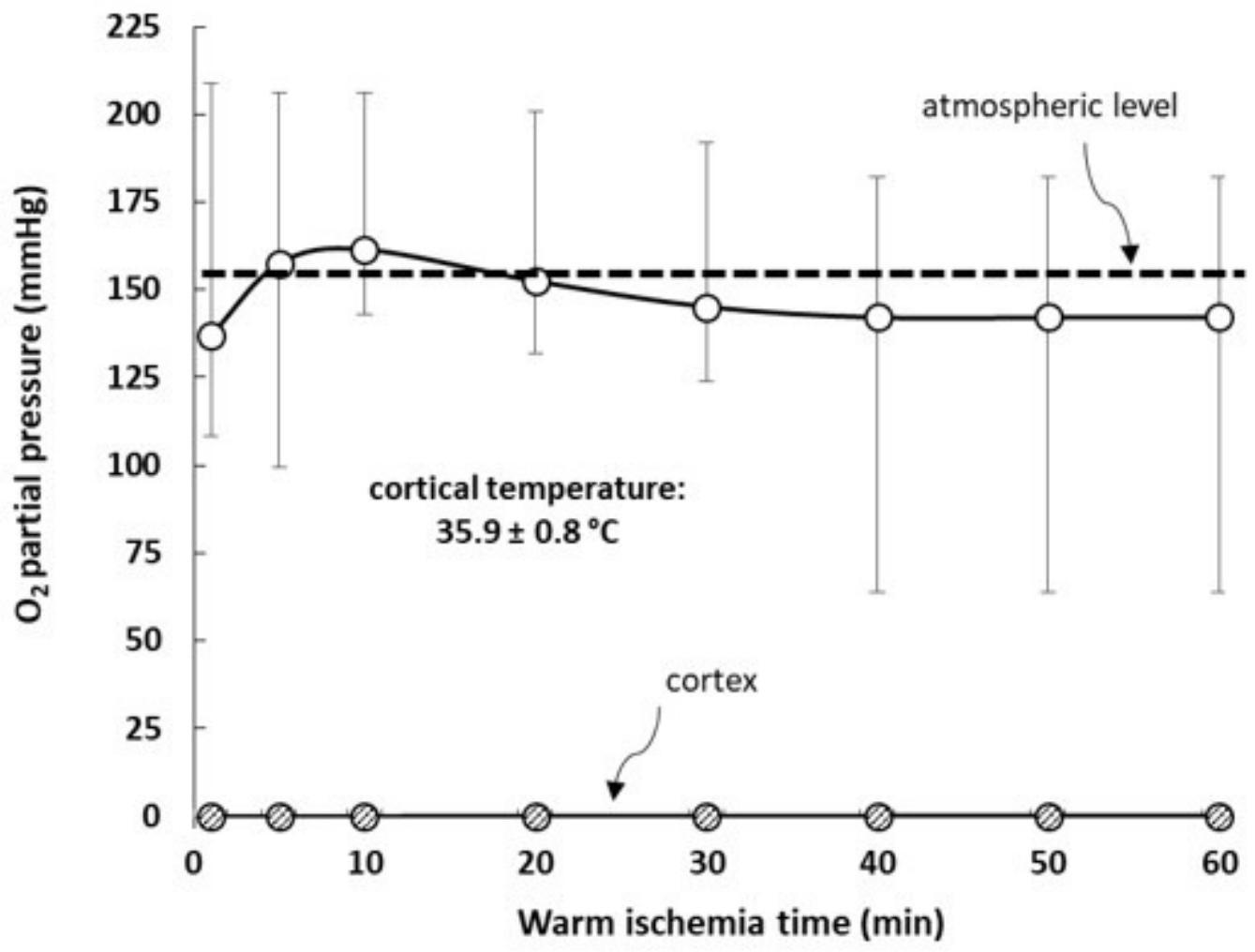




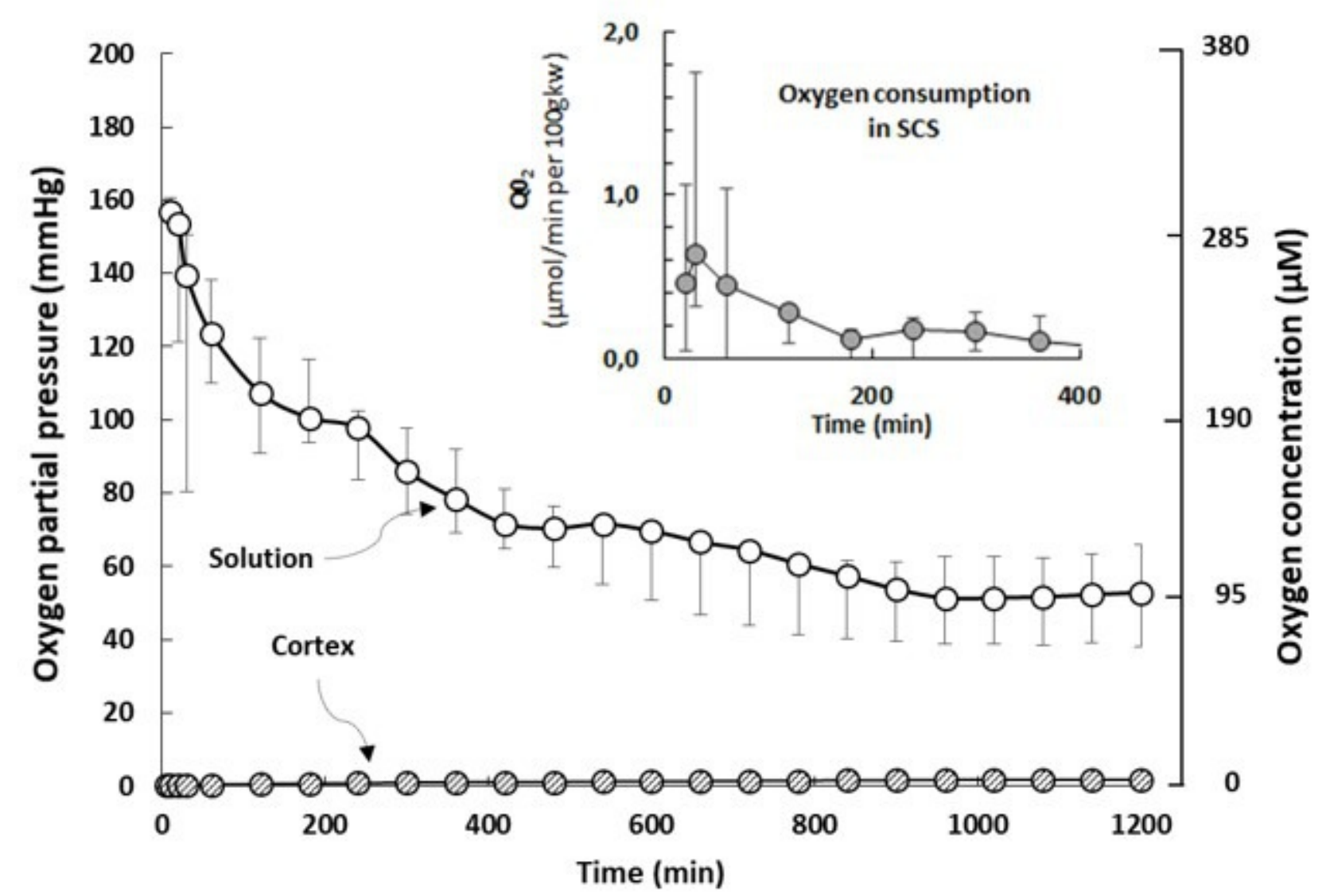




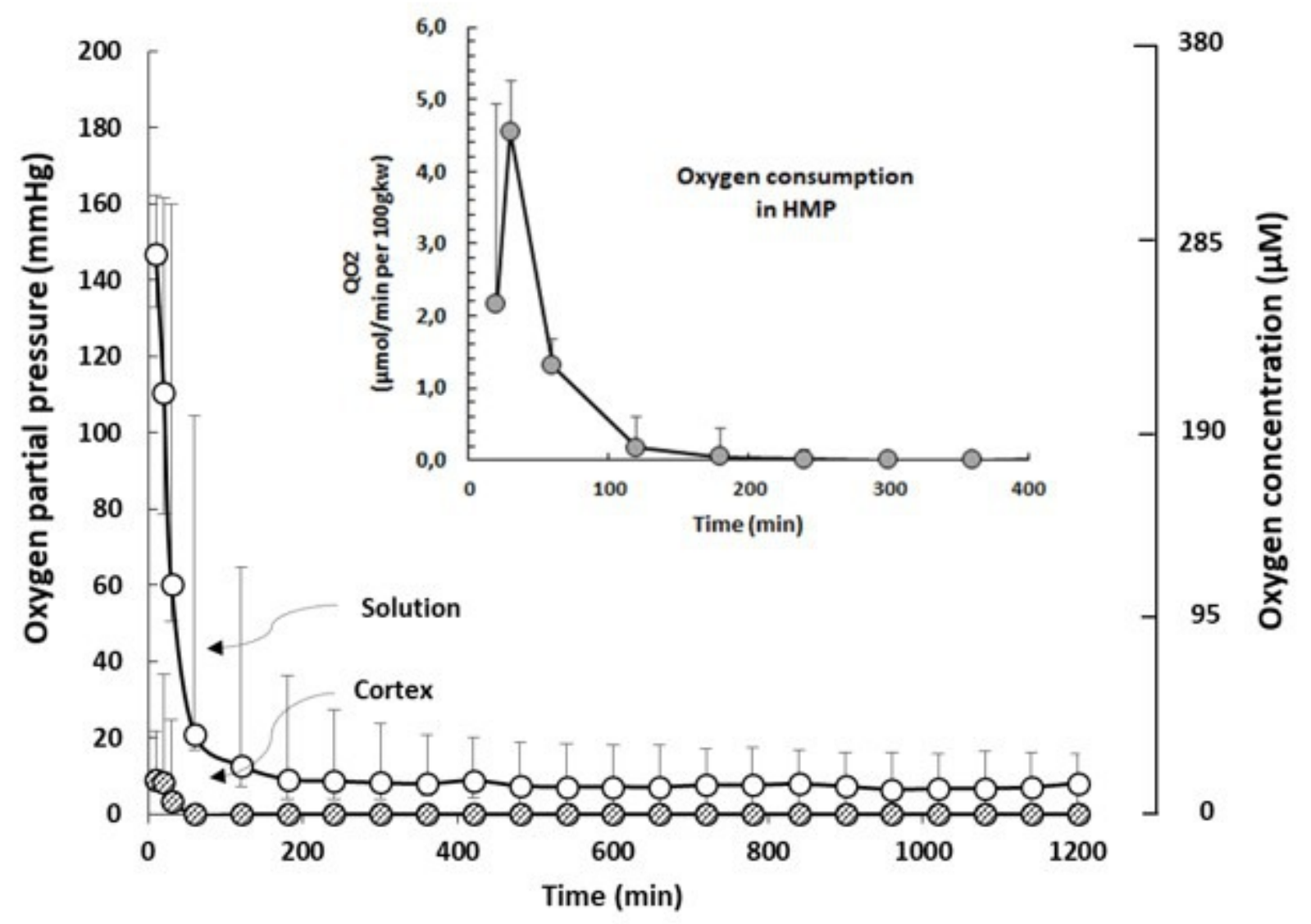




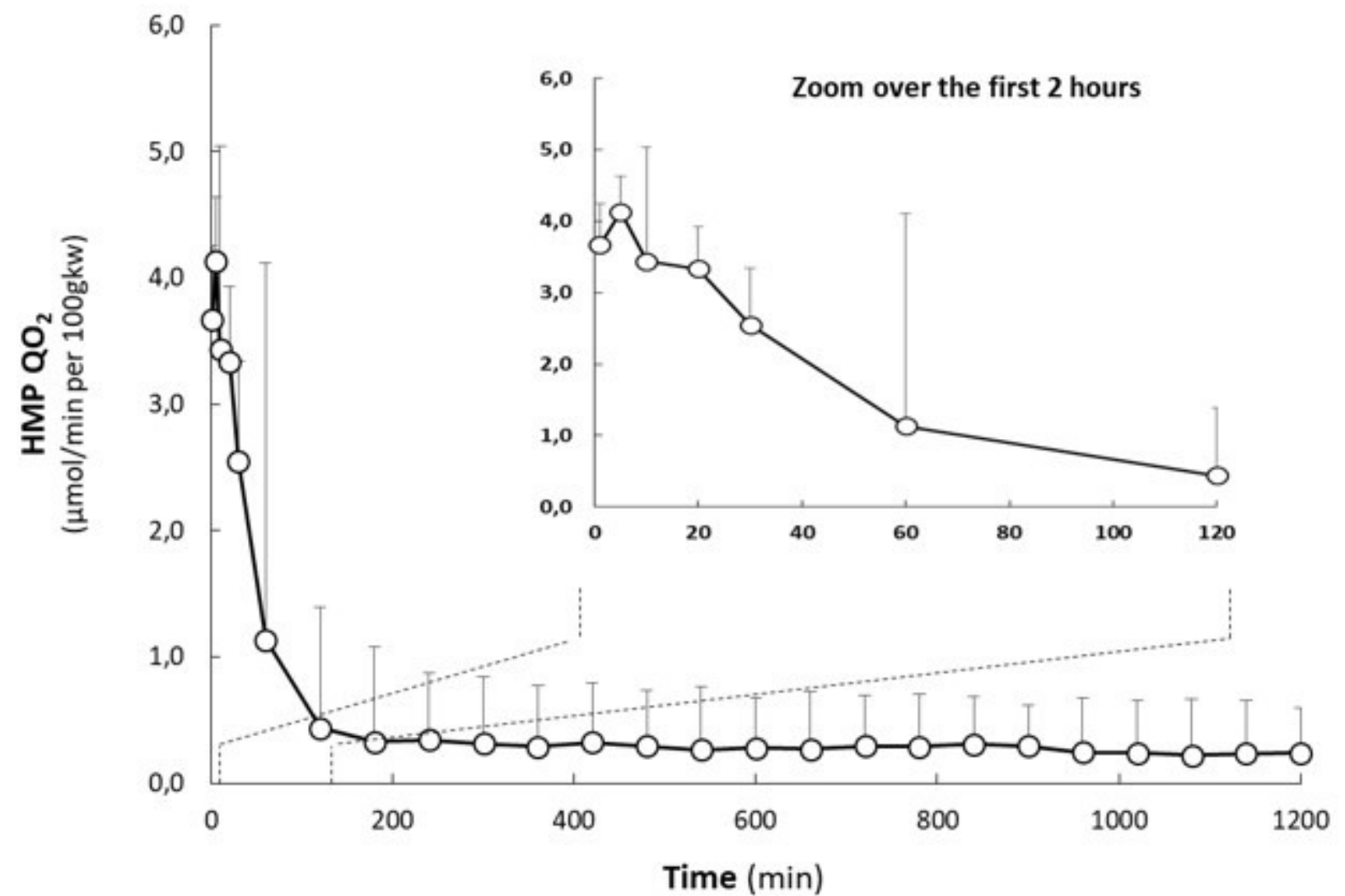




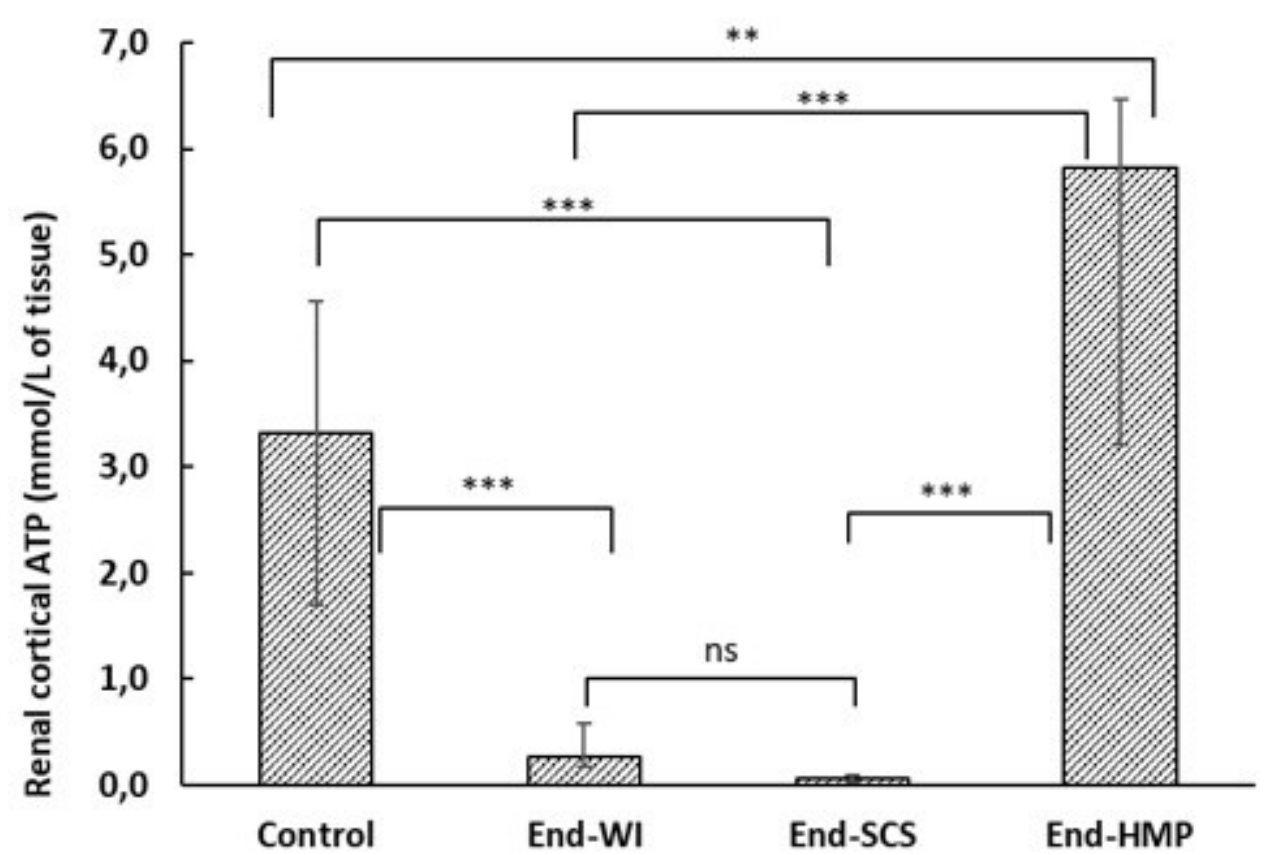



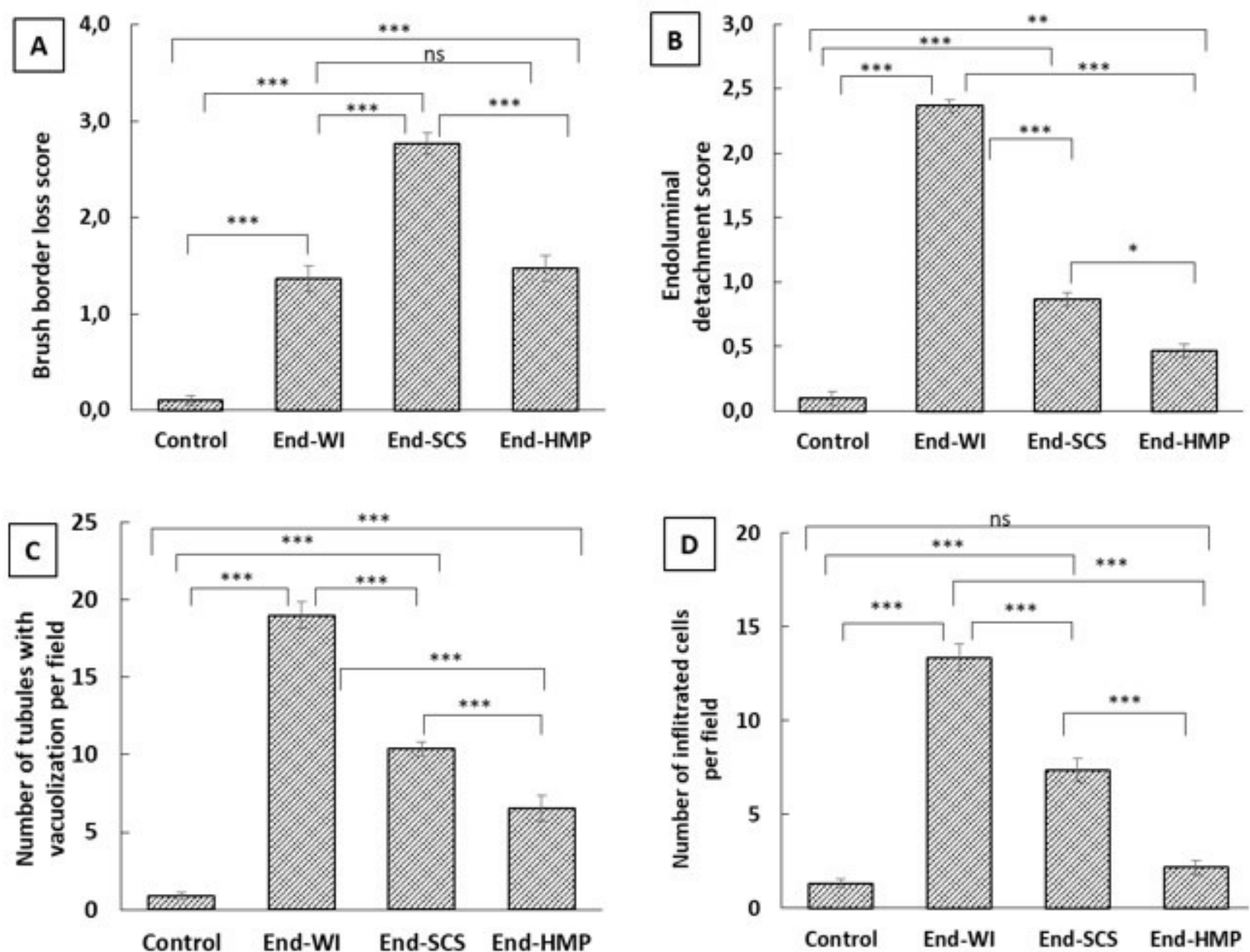